\title{
Mikro Elementlerin (Fe, Zn, B ve Mn), Şekerpancarında (Beta vulgaris L.) Kalite Kriterleri Üzerine Etkisi
}

\author{
*Amir RAHIMI ${ }^{*}$ Neşet ARSLAN ${ }^{2}$ Seyamak ESMZAD ${ }^{3}$ \\ ${ }^{1}$ Urmia Üniversitesi, Ziraat Fakültesi, Tarla Bitkileri Bölümü, Urmia,Iran \\ ${ }^{2}$ Ankara Üniversitesi, Ziraat Fakültesi, Tarla Bitkileri Bölümü, Ankara, Türkiye \\ ${ }^{3}$ Nagade Şekerpancarı Fabrikasi, Ziraat Birimi, Sulduz, Batı Azerbaycan, İran \\ *Sorumlu yazar e-posta (Corresponding author e-mail): emir10357@gmail.com
}

\begin{abstract}
Öz
Şekerpancarının (Beta vulgaris L.) rekabet gücünü artırmak amacıyla bir hayli yol alınmıştır. Şeker üretiminde pancarda bulunan şekerin tamamı kristalize edilememektedir. Şekerpancarı kalitesini tanımlayan bazı özellikler arasında şeker dışı maddeler şeker kristalizasyonunu etkiler. Mikro elementler, bitkileri kalite ve verim açısından etkilemektedir. Bu denemede kullanılan mikro elementlerin ( $\mathrm{Fe}, \mathrm{Zn}, \mathrm{B}$ ve $\mathrm{Mn}$ ), şekerpancarında kalite kriterleri üzerine olan etkisi araştırılmıştır. Bu araştırma 2005-2006 yıllarında İran'ın şekerpancarı açısından önemli bölgelerinden biri olan Batı Azerbaycan'ın Sulduz bölgesinde bulunan şekerpancarı fabrikasında gerçekleştirilmiştir. Araştırma tesadüf blokları deneme desenine göre, 4 tekerrürlü olarak kurulmuştur. Örneklerdeki şeker oranı, Na, K ve N miktarları Betalyser Sistemi (Sucromat otomatik sakkarimetre, alev fotometre ve testamin fotometre) kullanılarak analiz edilmiştir. Bu sonuçlardan bilgisayar programı yardımıyla kristalize edilebilen şeker miktarı, alkalinite ve melastaki şeker oranı belirlenmiştir. Elde edilen bulgulara göre; şeker oranı \%15.48-17.77, K varlığı 6.65-7.86 (meq/100 g pulp), Na varlığı 1.30-1.95 (meq/100 g pulp), N varlığı 1.34-7.95 (meq/100 g pulp), alkalinite 3.12-7.95, kristalize edilebilen şeker oranı \%12.32-13.81, şeker randımanı \%77.72-79.59 ve melastaki şeker oranı \%3.25-3.95 arasında değişmiştir.
\end{abstract}

Anahtar Kelimeler: Alkalinite, Sulduz, şeker randımanı, mikro elementler

\section{Effect of Micronutrients (Fe, Zn, B and Mn) on Quality Criteria of Sugar Beet (Beta vulgaris L.)}

\begin{abstract}
In order to increase sugarbeet competitiveness it is necessarry to consider many things. It is not possible to crystalyze all sugar in sugarbeet. Some characteristics of sugarbeet that determine the quality of sugarbeet are non-sugar substances. Micronutrients such as environmental factors can affect the yield and quality in plants. The aim of the study was to find the effects of micronutrients ( $\mathrm{Fe}, \mathrm{Zn}, \mathrm{B}$ and $\mathrm{Mn}$ ) on quality of sugarbeet. The study was carried out during 2005-2006 at the agricultural lands of Sulduz region (most important region in terms of sugarbeet production), West Azerbayjan Province, Iran affiliated to the Sugarbeet Factory of the region using randomized complete block design with four replications. The sugar percentage and the amounts of $\mathrm{Na}, \mathrm{K}$ and $\mathrm{N}$ were analysed by Betalyser System (Sucromat automatic Saccharometer, flame photometer and testamin photometer). Crystallized sugar percentage, alkalinity, the precentage of sugar in molasses and sugar yield were also determined. The findings showed that sugar percentage, amount of $\mathrm{K}, \mathrm{Na}, \mathrm{N}$, alkalinity, crystallized sugar percentage, sugar yield and percentage of sugar in molasses were between 1548-15.48$17.77 \%, 6.65-7.86$ (meq/100 g pulp), 1.30-1.95 (meq/100 g pulp), 1.34-7.95 (meq/100 g pulp), alkalinity 3.12$7.95,12.32-13.81 \%, 77.72-79.59 \%$ and $\% 3.25-3.95 \%$ respectively.
\end{abstract}

Keywords: Alkalinity, Sulduz, sugar yield, micronutrients

\section{Giriş}

S ekerpancarında şeker varlığı ve Şeker dışı maddeler (a-amino N, Na, K, invert şeker, dêkstran, rafinoz vs.) şekerpancarı kalitesini tanımlayan bazı özellikler içerisinde yer almaktadır (Vukov 1971; Sohrabi et al. 2006). Şeker dışı maddelerin verileri, kristalize edilebilen şeker oranını belirlemek için birçok formülde yer almaktadır (Sheykhuleslami 1996). 
Şekerpancarında adı geçen elementlerin bulunması kristalizasyon aşamasında bir engel oluşturur ve daha fazla şekeri melasa doğru götürür (Hilde et al. 1983) ve bu nedenle şeker randımanı tarladaki üretilen şekerpancarına bağlıdır (Alexander 1971). Ekolojik şartları şekerpancarı üretimine elverişli olması ve İran'ın Batı Azerbaycan ilinin Sulduz yöresinde (36:57 E, 45:22 N) şekerpancarı fabrikası bulunması nedeniyle, şekerpancarı bitkisel üretim açısından bu yöre ve çevresinde en önde gelen ürünlerden biridir. Şekerpancarı üretimi, üreticilerle akdedilen "Şekerpancarı Üretim Sözleşmesi" hükümlerine uygun olarak yapılmaktadır (Aghaalinejad 2011).

Tarımsal üretimde verim ve kalite üzerine etki eden en önemli faktörlerin başında toprak verimliliği gelir. Bazı koşullarda besin elementi fazlalığı veya besin elementi yetersizliği bitkiler tarafından diğer besin elementlerinin alınmasına engel olurken, verim ve kaliteyi de olumsuz etkilemektedir. Öte yandan, toprakların fiziksel ve kimyasal özellikleri belirlenerek, bu özellikler ile topraktaki besin elementleri arasındaki ilişkilerin bilinmesi, yapılacak gübrelemeden en yüksek faydanın sağlanması açısından önemlidir (Çimrin ve Boysan, 2006). Topraklarda bulunan mikro element konsantrasyonu oldukça düşüktür $\left(\mathrm{mg} \mathrm{kg}^{-1}\right.$ veya daha az). Bakır (Cu), çinko (Zn), mangan (Mn), demir (Fe), molibden (Mo) ve bor (B) elementleri bitki büyümesi için gerekli olan elementlerdir ve mikroelementler olarak isimlendirilir. Bor hariç bu elementler aynı zamanda ağır metallerdir ve bunların yüksek konsantrasyonları bitkiler için toksiktir (Webber 1981). Toprakta mikro elementlerin sadece küçük bir kısmı gereklidir. Amerika'da $\mathrm{Cu}, \mathrm{Zn}$, $B$, $\mathrm{Fe}$ ve $\mathrm{Mn}$ gibi mikro elementler bitki ihtiyacına göre gübreler harmanlama yapılarak ilave edilmektedir. Bu gübreler, topraklarda ürün yetiştirilmesi için önemli mikro element kaynaklarıdır (Webber 1981; Bakırcıoğlu 2009). FAO nun rakamlarına göre dünyada tüketilen gübrenin \%69'u gelişmiş ülkelerde, \%31'i ise gelişmekte olan veya az gelişmiş ülkelerde tüketilmektedir. Bitki beslenmesi yolu ile yüksek verim, kaliteli ve sağlıklı ürün için yapılması gerekenler, gübre ihtiyacının belirlenmesi, gübre çesidi ve miktarı, uygulama yöntemi, uygulama sıklıgı ve zamanı ile ilgili kayıtlar önem taşımaktadır (FAO, 2009).

Bor (B), demir (Fe), mangan (Mn), çinko $(\mathrm{Zn})$, bakır $(\mathrm{Cu})$, klor $(\mathrm{Cl})$ ve molibden (Mo) şekerpancarı tarımında gereken mikro elementlerdir (Draycott and Christenson 2003) ancak Bor (B), demir (Fe), mangan (Mn) ve çinko $(\mathrm{Zn})$ gibi elementlerin yetersizliğine çok hassastır. Tüm bitkilerin gelişmesi için demir önemli bir mikro elementtir ve bu elementin yetersizliği taktirde yaprakların hücrelerinde yeterince klorofil üretilemez (Malakooti and Tehrani 2000) ve sonuçta dışarıdan $\mathrm{CO}_{2}$ alımı ve biyokimyevi dönüşümü azalır (Sharman and Sanwal 1992). Bor başka bir mikro element olarak bitkilerin doğal gelişmesini ve büyümesini sağlar; diğer taraftan hücre düvarlarının oluşumunda önemli etkiye sahiptir. Bu elementin yetersizliği taktirde bitkinin büyümesi durur ve verimi düşer (Hu and Brown, 1997). Mangan, nitrojen metabolizması, Co2 asimilasyonu ve oksinin sentezinde enzimatik sistemlerde etkilidir (Tisdale et al. 1990). Çinko elementi bitkilerin bir çok enzimatik sistemlerinde katalizör veya aktivatör olarak görev almaktadır. Bu element bitkilerde protein üretiminde ve parçalanmasında da etkilidir (Malakooti and Tehrani 2000).

Toprağın bitki besinlerini yeterince bitkiye sağlayamaması durumunda yapılması gereken işlem gübrelemedir. Konvansiyonel gübreleme yöntemlerinin terk edilerek yeni yöntemlerin uygulanması kaçınılmaz hale gelmiştir. Günümüzün bitki besleme ve gübreleme uygulamaları, sadece yüksek ürün sağlayan işlemler şeklinde değil, aynı zamanda yüksek kaliteli ve sağlıklı tarımsal üretime yönelik, çevre ve doğal kaynakları koruyan, izlenebilir olacak sekilde planlanarak yürütülmelidir. Bitkisel üretimde 21. yüzyılda hakim olan yaklaşım artık kaliteli üretimdir (Fresco 2004). Yaprak gübreleri, son yıllarda İran'da da kullanılmaya başlanmıştır. Toprakta bitki besin maddesi yoksa, iklim ve toprak şartları nedeniyle bitki besin maddesi alınamıyorsa, fotosentez organı olan yapraktan bitkiye zorunlu olarak yaprak gübreleri kanalıyla yetersiz olan besin maddesi verilebilir. Bu şekilde bilinçli gübreleme çiftçilere önemli oranda ekonomik kazançlar sağlayabilir. Şekerpancarı üretiminde yaprak gübreleri su ile karıştırılarak gelişme döneminin başlangıcında 2-3 hafta ara ile 2-3 kez akşamüstü serin ve rüzgarsız saatlerde yapraklara püskürtülür. Diğer şekerpancarı üreten ülkelerde olduğu gibi, İran'da da şekerpancarından şeker üretim maliyeti ve verimliliği açısından önemli sorunlar bulunmaktadır. Bu sorunlardan bir tanesi şekerpancarın üretiminde besin elementlerinin yeterli ve dengeli olmayışından kaynaklanıp, verim ve kaliteyi etkilemektedir. Şeker fabrikalarına verilen ham madde, nitel biçimde kaliteli olursa artırıcı bir etmen olarak, şeker sanayinin ilerlemesine yardımcı olup, bu ilerleme doğrudan ve dolaylı şekilde çifçinin 
hayatına yansıyacaktır. $\mathrm{Bu}$ araştırmada kullanılan mikro elementlerin ( $\mathrm{Fe}, \mathrm{Zn}, \mathrm{B}$ ve $\mathrm{Mn}$ ), şekerpancarı kalitesini etkileyen N, Na ve K gibi şeker dışı maddelerin miktarını, ne kadar değiştirebilirliği veya başka bir deyimle şekerpancarında kalite kriterleri üzerine olan etkisi araştırılmıştır.

\section{Materyal ve Yöntem}

Bu araştırma, 2005-2006 yıllarında İran'ın şekerpancarı açısından önemli bölgelerinden biri olan Batı Azerbaycan ilinin Sulduz yöresindeki fabrikaya ait bir tarlada kurulmuştur. $\mathrm{Bu}$ yöre Urumiye Gölü, Urumiye, Mahabad (Sablağ), Miyandab (Goşaçay) ve Piranşehr (Khana) şehirleri, Türkiye ve Irak ülkelerince sınırlanmıştır. Yörenin yüksekliği 1000-2100 m arasında değişmektedir. Drenajı iyi olan topraklarının derinliği yarı derin ve derin arasında, toprak tekstürü ise orta ve ağır topraklar gurubu arasındadır. Sulu tarımda kullanılan tarlaların eğimi $2-5^{\circ} \mathrm{C}$ arasında değişmektedir. Meteoroloji verilerine göre yıllık ortalama sıcaklık $11.3-13.71^{\circ} \mathrm{C}$ arasındadır. Yaz ortalama sıcaklığı $22.76^{\circ} \mathrm{C}$ ve kış ortalama sıcaklığı $2.45^{\circ} \mathrm{C}$, en soğuk aylar Aralık-Ocak ($0.3^{\circ} \mathrm{C}$ ), en sıcak aylar Temmuz- Ağustos $\left(24.21^{\circ} \mathrm{C}\right)$ ve ortalama yağış miktarı ise 326.43 $\mathrm{mm}$ dir (Aghaalinejad, 2011).

Deneme tarlasına ait toprak örnekleri tarlayı temsil edecek şekilde $0-30 \mathrm{~cm}$ toprak derinliğinden toprak örneği alınmıştır. Alınan toprak örnekleri havada kuru hale geldikten sonra, 2 mm'lik elekten geçirilerek analizler için hazırlanmıştır. Toprak örneği Sulduz Toprak Analiz Laboratuarı'na gönderilmiştir. Analiz sonuçları Çizelge 1'de gösterilmektedir.

Çizelge1. Deneme yeri toprak analiz sonuçları Table 1. Soil analysis results of experimental area

\begin{tabular}{ll}
\hline $\mathrm{P}_{2} \mathrm{O}_{5}(\mathrm{~kg} / \mathrm{da})$ & 9.1 \\
$\mathrm{~K}_{2} \mathrm{O}(\mathrm{kg} / \mathrm{da})$ & 397 \\
Organik madde $(\%)$ & 0.70 \\
Toplam azot $(\%)$ & 0.06 \\
$\mathrm{TNV}(\%)$ & 23.0 \\
$\mathrm{SP}(\%)$ & 55 \\
$\mathrm{EC}(\mathrm{dS} / \mathrm{m})$ & 0.721 \\
$\mathrm{Kil}(\%)$ & 39 \\
$\mathrm{TIn}(\%)$ & 43 \\
$\mathrm{Kum}(\%)$ & 18 \\
$\mathrm{Ph}$ & 7.81 \\
$\mathrm{Fe}\left(\mathrm{mg} \mathrm{kg}^{-1}\right)$ & 9.1 \\
$\mathrm{Zn}\left(\mathrm{mg} \mathrm{kg}^{-1}\right)$ & 1 \\
$\mathrm{~B}\left(\mathrm{mg} \mathrm{kg}^{-1}\right)$ & 0.3 \\
$\mathrm{Mn}\left(\mathrm{mg} \mathrm{kg}^{-1}\right)$ & 11.5 \\
\hline
\end{tabular}

Araştırma tesadüf blokları deneme desenine göre 4 tekerrürlü olarak kurulmuştur. Araştırmada Şirin çeşidi kullanılmıştır; bu çeşit İran tarım bakanlığının şekerpancarı araştırma merkezince ıslah ve üretilmiş olan bir hibrit çeşididir. Şirin çeşidi sapa kalkmaya dayanıklı olup, şeker oranı yüksektir (Farzaneh et al. 2014).

Tohumların ekimi sıra arası $50 \mathrm{~cm}$ ve her parselde 6 sıra olacak şeklinde el markörü ile işaretlenen çizgilere 10.04.2006 tarihinde yapılmıştır. Ekim zamanında çıkış açısından, yağış ve toprak nemi uygun durumda olmuştur. Fosfor gübresinin 2/3'ü sonbaharda sürümde taban gübresi olarak pulluk altına, 1/3 'ü ise ilkbaharda tohum yatağı hazırlığında azot gübresi ile beraber verilmiştir. Öngörülen azotun yarısı tohum yatağı hazırlamadan önce tırmık altına, diğer yarısı da baş gübresi olarak en geç son ot çapası altına verilmiştir. Toprak Analiz Laboratuarın tavsiyesine uyarak $25 \mathrm{~kg} \mathrm{da}^{-1}$ saf $\mathrm{N}$ ve $10 \mathrm{~kg} \mathrm{da}^{-1}$ saf $\mathrm{P}_{2} \mathrm{O}_{5}$ gübre hesabıyla, tüm parsellerde kullanılmıştır. Çıkışlardan sonra yabancı otlara karşı kimyasal mücadele yapılmıştır. Bitkiler ekim zamanlarına göre 2-4 yapraklı döneme eriştikten sonra sıra üzeri ortalama $20 \mathrm{~cm}$ olacak şekilde seyreltme işlemine tabi tutulmuştur. Yabancı ot yoğunluğu dikkate alınarak, pancar yaprağı toprağı örtünceye kadar çapa işlemine devam edilmiştir. Toplam 4 kez çapalama yapılmış ve bu işlem genellikle sulamadan sonra yapılarak yabancı otların gelişimi engellenmiş ve kaymak tabakasının kırılması sağlanmıştır. Yaprak gübreleri su ile karıştırılarak gelişme döneminin başlangıcında 2-3 hafta ara ile 2 kez akşamüstü serin ve rüzgarsız saatlerde yapraklara püskürtülmüştür. Yaprak gübresi olarak kullanılan mikro elementlerin hepsi (Fe, Zn, B ve $M n$ ) Kavin Tous şirketinden temin edilmiştir. Demir (Fe), Çinko (Zn), Bor (B) ve Mangan (Mn) şirketin tavsiyesine göre 1 litre ha-1, 1 litre ha-1, 2 litre ha-1, 3 kg ha-1 hesabıyla kullanılmıştır. Pancar bitkisinin gelişme dönemi boyunca topraktaki nem durumu dikkate alınarak $7 \mathrm{kez}$ olmak üzere salma sulama işlemi uygulanmıştır. Ağustos ayının başlarında şeker pancarında görülen yaprak bitine karşı sistemik ilaç kullanılarak mücadele yapılmıştır. Ayrıca ağustos ayının ortalarına doğru külleme hastalığına rastlanmıştır. Bu nedenle 5 Ağustos olmak üzere bir kez ilaçlama yapılarak hastalık kontrol altına alınmıştır. Bitkilerin hasadı 21 Ekim 2006 tarihinde yapılmıştır. Araştırmada; şeker oranı, $\mathrm{Na}, \mathrm{K}$ ve $\mathrm{N}$ miktarları, kristalize edilebilen şeker oranı, alkalinite ve melastaki şeker oranı özellikleri ele alınmıştır. Alınan 
pancar numuneleri özenle yıkanıp veenema cihazı ile pulplar (hamur) hazırlanmıştır. Hazırlanan pulp numuneleri kapaklı özel kaplara yerleştirilip, kimyevi analizlerin yapılmasına dek dip frizde $\left(-20^{\circ} \mathrm{C}\right)$ bekletilmiştir. Kimyevi analizler İsfahan şekerpancarı fabrikalarının ortak araştırma laboratuarında gerçekleştirilmiştir. Numuneler laboratuar sıcaklığında (yaklaşık $20^{\circ} \mathrm{C}$ ) donu açılana kadar bekletilmiş ve 26 gram pulp numunesi kimyevi analizler için kullanılmıştır. Hazırlanmış çözelti Betalyser Sistemi (Sucromat otomatik sakkarimetre, alev fotometre ve testamin fotometre)'ne konarak, numunedeki şeker oranı, $\mathrm{Na}, \mathrm{K}$ ve $\mathrm{N}$ varlığı belirtilmiştir. Bu verileri kullanarak numunelerin alkalinitesi, Melastaki şeker oranı-Molasses sugar (MS), kristalize edilebilen şeker oranı-White sugar content (WSC) ve şeker randımanı-Extraction coefficient of sugar (ECS) hesaplanmıştır (Sohrabi and et al., 2006). Özelliklerin hepsinde EXCEL programı kullanarak ortalama hesaplanmış ve eğimler çizilmiştir.

\section{Bulgular ve Tartışma}

Elde edilen bulgulara göre, farklı gübrelemelerden alınan şekerpancarı numunelerinin ortalama şeker oranı \%15.4817.77 arasında değişmiştir; en yüksek oran kontrole ve en düşük oran demir kullanımına aittir. Şekerpancarı numunelerinde ortalama K varlığı 6.65-7.86 (meq/100 g pulp) arasında değişmiş, en düşük ve en yüksek varlık sırasıyla demir ve kontrolde bulunmuştur. Numunelerdeki ortalama Na varlığı 1.30 - 1.95 (meq/100 g pulp) arasında değişmiştir; K varlığında olduğu gibi en düşük ve en yüksek varlık sırasıyla demir ve kontrolde kaydedilmiştir. N varlığının en düşük miktarı (1.34 meq/100 g pulp) bor uygulamasında ve en yüksek miktarı (3.15 meq/100 g pulp) kontrolde bulunmuştur. Alkalinite özelliğine gelince en düşük rakam (3.12) kontrolde ve en yüksek rakam (7.95) bor kullanımında bulunmuştur. Kristalize edilebilen şeker oranının en düşük miktarı (\%12.32) demir uygulamasında ve en yüksek miktarı (\%13.81) kontrolde görünmüştür. Şeker randımanı kriteri ile ilgili en düşük oran (\%77.72) kontrolde ve en yüksek oran(\%79.59) demir uygulamasında bulunmuştur.

Melastaki şeker oranı özelliğine gelince en düşük oran (\%3.25) demir kullanımında ve en yüksek oran (\%3.95) kontrolde kaydedilmiştir (Çizelge 2.). Şekerpancarı topraktaki demir, çinko, bor ve mangan gibi elementlerin az miktarda bulunmasına, hassastır (Malakooti ve Tehrani, 2000). Araştırmayı yaptığımız deneme yerinin toprağındaki demir ve bor düşük seviyelerde, çinko ve mangan orta seviyelerde bulunuyordu. Demir gübresinin kullanımı, şekerpancarı numunelerındeki $\mathrm{K}, \mathrm{Na}$ ve $\mathrm{N}$ varlıklarını kontole nazaren düşürmüştür; bununla birlikte istemediğimize rağmen, şeker oranında da azalma görünmüştür. Demir uygulaması sonucu $\mathrm{K}$, $\mathrm{Na}$ ve $\mathrm{N}$ varlıklarının düşmesi ile birlikte, şeker randımanında yükselmeye sebep olmuştur. Demirde olduğu gibi, diğer mikro elementlerin kullanımı da aşağı yukarı $\mathrm{K}$, $\mathrm{Na}$ ve $\mathrm{N}$ varlıklarının düşmesine sebep olmuş, şeker randımanını çoğaltmıştır ancak şeker oranında düşüş kaydedilmiştir.

Gobarah et al. (2014) gerçekleştirdikleri iki yıllık bir denemde mikro elementlerin etkisini şekerpancaının verim ve kalitesi kriterleri üzerine denemişlerdir. Bu araştırmanın sonucuna göre şeker oranı demir gübresi kullanıldığında, kontrola göre \%1.36'lık bir artış göstermiştir. Çinko, Mangan ve Bor kullanıldığında ise şeker oranında atış görünmüştür. $\mathrm{Bu}$ elementlerin hepsi birlikte uygulandığında, kontrola göre \%1.75’lik bir artış

Çizelge 2. Şeker Oranı (\%) (I), K (II), Na (III) ve N (IV) Varlığı (meq/100g pulp), Alkalinite (V), Kristalize Edilebilen Şeker Oranı (\%) (VI), Şeker Randımanı (\%) (VII) ve Melasın Şeker Oranı (\%) (VIII)

Table 2. Sugar percentage \% (I), K (II), Na (III) and N (IV) Content (meq/100g pulp), Alkalinity (V), Crystallized sugar percentage (\%) (VI), Sugar Yield (\%) (VII) and Percentage of Sugar in Molasses (\%) (VIII)

\begin{tabular}{ccccccccc}
\hline & $\mathrm{I}$ & $\mathrm{II}$ & $\mathrm{III}$ & $\mathrm{IV}$ & $\mathrm{V}$ & $\mathrm{VI}$ & $\mathrm{VII}$ & $\mathrm{VIII}$ \\
\hline \multirow{2}{*}{ Kontrol } & 17.77 & 7.86 & 1.95 & 3.15 & 3.12 & 13.81 & 77.72 & 3.95 \\
& \pm 0.29 & \pm 0.60 & \pm 0.09 & \pm 0.27 & \pm 0.05 & \pm 0.55 & \pm 1.82 & \pm 0.26 \\
$\mathrm{~B}$ & 15.94 & 6.94 & 1.44 & 1.34 & 7.95 & 12.65 & 79.17 & 3.29 \\
& \pm 1.80 & \pm 0.09 & \pm 0.10 & \pm 0.63 & \pm 3.60 & \pm 1.68 & \pm 1.58 & \pm 0.12 \\
$\mathrm{Fe}$ & 15.48 & 6.65 & 1.30 & 1.47 & 5.71 & 12.32 & 79.59 & 3.25 \\
& \pm 0.42 & \pm 0.06 & \pm 0.24 & \pm 0.34 & \pm 1.42 & \pm 0.45 & \pm 0.75 & \pm 0.05 \\
$\mathrm{Mn}$ & 16.15 & 6.95 & 1.31 & 2.43 & 3.41 & 12.81 & 79.28 & 3.35 \\
& \pm 0.24 & \pm 0.54 & \pm 0.26 & \pm 0.32 & \pm 0.13 & \pm 0.06 & \pm 1.56 & \pm 0.30 \\
$\mathrm{Zn}$ & 15.73 & 6.83 & 1.63 & 1.91 & 4.76 & 12.35 & 78.58 & 3.37 \\
& \pm 0.68 & \pm 0.58 & \pm 0.01 & \pm 0.56 & \pm 1.08 & \pm 0.43 & \pm 0.67 & \pm 0.26 \\
\hline
\end{tabular}


kaydedilmiştir. $\mathrm{K}$ valrığı kriterine gelince, kontrola göre, gübre uygulamalrının hepsinde bir düşüş görünmüştür ancak bu düşüş elementlerin hepsi birlikte kullanıldığında daha fazla bulunmuştur. Farklı gübre uygulamalarında $\mathrm{Na}$ varlığı, K varlığı gibi bir sonuç göstermiştir hatta elementlerin hepsi birlikte kullanıldığında en fazla düşüş kaydedilmiştir. Farklı gübre uygulamalarında, N varlığı da $\mathrm{Na}$ ve K varlığına benzer bir sonuç ortaya koymuştur. Kristalize edilebilen şeker oranı özelliği ile ilgili en düşük oran (\%15.57) kontrol ve en yüksek oran (\%17.56) elementlerin hepsinin kullanımına aittir; ikinci sırada ise demir uygulaması bulunmaktadır. Şeker randımanı kriterinin en yüksek oranı (\%84.61) elementlerin hepsinin kullanımında ve en düşüğü (\%81.25) kontolda görünmüştür. Melastaki şeker oranının en yüksk oranı (\%3.66) ve en düşük oranı (\%3.41) sırasıyla elementlerin hepsinin kullanımı ve kontrole aittir (Gobarah et al. 2014). Rahimi ve Arslan (2012a), yaptıkları bir denemde, şekerpancarı kalitesi üzerine toprak tekstürünün etkisini araştırmışlardır; bulgularına göre, şeker oranı \%16.16-17.82, K miktarı 3.88-4.64 (meq/100 g pulp), Na miktarı 1.34-3.57 (meq/100 g pulp), N miktarı 1.58-3.08 (meq/100 g pulp), Alkalite 2.73-5.77, Kristalize edilebilen şeker oranı \%12.99-15.19, Şeker randımanı \%79.31-86.11 ve Melastaki şeker oranı \%2.32-3.06 arasında değişmektedir. Gobarah et al. (2011), iki yıllık bir denemede şekerpancarı üzerine potasyum gübresi uygulamışlardır. $\mathrm{Bu}$ denemenin sonucuna göre, 2008-2009 tarım sezonunda, ortalama şeker oranı \%19.28-21.07, K varlığı 5.41-6.54 (meq/100 g pulp), Na varlığı 1.722.02 (meq/100 g pulp), N varlığı 3.84-4.39 (meq/100 g pulp), Kristalize edilebilen şeker oranı \%15.75-17.78, Şeker randımanı \%81.7084.41 ve Melastaki şeker oranı \%3.23-3.56 arasında değişmiştir; 2009-2010 tarım sezonunda ise, ortalama şeker oranı \%18.6121.04, K varlığı 4.07-7.35 (meq/100 g pulp), Na varlığı 1.79-2.46 (meq/100 g pulp), N varlığı 3.41-4.99 (meq/100 g pulp), Kristalize edilebilen şeker oranı \%14.58-17.65, Şeker randımanı \%80.73-83.87 ve Melastaki şeker oranı \%2.794.03 arasında değişmiştir. Rahimi ve Arslan (2012b), yaptıkları bir denemde, şekerpancarı kalitesi üzerine toprak Ph'sı ve tuzluluğu etkisini araştırmışlardır; bulgularına göre, şeker oranı \%16.16-18.08, K miktarı 3.95-5.04 (meq/100 g pulp), Na miktarı 1.44-3.57 (meq/100 g pulp), N miktarı 1.43-3.88 (meq/100 g pulp), Alkalite 2.02-5.92, Kristalize edilebilen şeker oranı \%12.99-15.48, Şeker randımanı \%79.31-85.45 ve Melastaki şeker oranı \%2.60-3.29 arasında değişmektedir. Jaliliyan et al. (2001), iki yıl süre içerisinde, şekerpancarınd su kullanımı ve azotlu gübre faktörlerinin etkisini araştırmışlardır. Bu araştırmanın sonucuna göre, ortalama şeker oranı \%18.51-21.81, N varlığı 0.93-8.95 (meq/100 g pulp) ve Kristalize edilebilen şeker oranı \%15.48-18.82 arasında değişmiştir. Çamaş ve Ark.(2007) iki yıl süre içerisinde Türkiye'nin 5 farklı bölgesinde yürüttükleri bir denemede, ortalama şeker oranını \%13.22-15.38, K varlığını 3.63-6.15 (meq/100 g pulp), $\mathrm{Na}$ varlığını 0.37-0.91 (meq/100 g pulp), N varlığını 1.66-3.5 (meq/100 g pulp), Kristalize edilebilen şeker oranını \%10.79-13.12 ve Şeker randımanını 84.1489.33 arasında değiştiğini bulmuşlardır. Nourju and Baghayikiya (2004) tarafından İran'ın Batı Azarbaycan ilinin Khoy ilçesinde yapılan bir araştırma sonucuna göre, ortalama alkalinite oranı 2.22-4.52 arasında kaydedilmiştir.

\section{Sonuç}

Elde edilen sonuçlara göre; şeker oranı \%15.48-17.77, K varlığı 6.65-7.86 (meq/100 g pulp), Na varlığı 1.30-1.95 (meq/100 g pulp), N varlığı 1.34-7.95 (meq/100 g pulp), alkalinite 3.12-7.95, kristalize edilebilen şeker oranı \%12.32-13.81, şeker randımanı \%77.72-79.59 ve melastaki şeker oranı \%3.25-3.95 arasında değişmiştir.

\section{Kaynaklar}

Aghaalinejad M., 2011. Florsitic Evaluation of Plant Diversity in Naghadeh (Sulduz). A thesis in biology branch, Marand Islamic University. Marand, Iran. (Farsça)

Alexander J.T., 1971. Factors Affecting Quality. P: 371-381. In Johnson RT, Alexander JT, Rush GE, (Editör: Hawkes G.R.). Advances in sugar beet production; Principles and practices. The lowa State Univ. Press. Ames.IA

Bakırcıoğlu D.Ç, 2009. Toprakta Makro ve Mikro Element Tayini. Doktora Tezi, Trakya Üniversitesi Fen-Edebiyat Fakültesi Kimya Bölümü

Çamaş N., Çırak C. and Albayrak S., 2007. Yield and quality of sugarbeet growen under northern Turkey condition. Int. J. of Agricultural Reserch, 2(3): 296-301

Çimrin K.M. ve Boysan S., 2006. Van yöresi tarım topraklarının besin elementi durumları ve bunların bazı toprak özellikleri ile ilişkileri. Yüzüncü Yıl Üniversitesi, Ziraat Fakültesi, Tarım Bilimleri Dergisi, 16:105-111

Draycott A.P., Christenson D.R., 2003. Nutrients for sugar beet production: Soil-plant relationships. CABI Publishing 
FAO, 2009. How to feed the world 2050. Global agriculture towards 2050. High Level Expert Forum, Rome, 12-13 October 2009

Farzaneh S., Sadeghzadeh S., Fathollah Taleghani D., Cheghini M.A., Ghaderifar F. and Fresco L.O., 2004. Fertilizer and the Future. FAO Agricultur Department. www.fao.org

Gobarah M.E., Tawfik M.M., Zaghloul S.M. and Amin Gehan A., 2014. Effect of combined application of different micronutrients on productivity and quality of sugar beet plants (Beta vulgaris L.), International Journal of Plant \& Soil Science, 3(6): 589-598

Gobarah M.E., Mekki B.B., Mohamed M.H. and Tawfik M.M., 2011. Comparative efficiency of foliar and soil potassium application on sugarbeet productivity and quality. AmericanEurasian J. Agric. \& Environ. Sci., 10 (4): 626632

Hilde D.J., Bass S.R., Levos S. and Ellingson R.L., 1983. Grower practices system promotes beet quality improvment in the Red River Valley. J. Am. Soc. Sugar beet Technol., 22: 73-88

Hu H. and Brown P.H., 1997. Absorption of boron by plant roots. Plant and soil.193: 49-58

Jaliliyan A., Shirvani A.R., Nemati A. and Basati J., 2001. Effects of deficit irrigation on the production and economy of sugarbeet in Kermanshah region. J. of Sugarbeet, 17: 114. (Farsça)

Malakooti M.G. and Tehrani MM, 2001. Micronutrients roll in maximizing crop yield and improving qualitative of agricultural products. Tarbiat Modarres University. (In Persian)

Nourju A. and Baghayikiya M., 2004. Study on the irrigation scheduling effects in different growth stages on quantity and quality of sugarbeet in Khoy region. İran. J. of Sugarbeet, 20(1): 2738. (Farsça)
Rahimi A. ve Arslan N., 2012a. Toprak Tekstürünün Şekerpancarının (Beta vulgaris L.) Kalite Kriterleri Üzerine Etkisi. 1. Uluslararası Anadolu Şeker Pancarı Sempozyumu, Kayseri, Türkiye, 127-135

Rahimi A. ve Arslan N., 2012b. Toprak Tuzluluğu (EC) ve pH'sının Şekerpancarının (Beta vulgaris L.) Kalite Kriterleri Üzerine Etkisi. 1 Uluslararası Anadolu Şeker Pancarı Sempozyumu, Kayseri, Türkiye, 118-126

Sharman C.P. and Sanwal G.G., 1992. Effect of Fe deficiency on the photosynthetic system of maize. Journal of plant physiology, 1992; 140: 527-530

Sheykholeslami R., 1996. Şeker üretimi ve şekerpancarında kaliteyi tanımlamak için formüllerin daha kullanışlı yapmak, Şekerpancarı bilimsel dergisi, 1-2: 72. (Farsça)

Sohrabi Y. and et al., 2006. Investigation of limited irrigation and root harvesting dates on yield and some of quality charactrestices of sugarbeet. J. of Pajouhesh and Sazandeghi. 70: 8-15

Tisdale S.L., Nelson W.L. and Beaton J.D., 1990. Soil Fertility and Fertilizers. $4^{\text {th }}$ ed. Macmillan Publishing Company. New York

Vukov K., 1971. Şekerpancarının Fizik ve Kimyası. T.Ş.F.A.Ş., Yayınları: 208: 97, Ankara

Webber J., 1981. "Trace Metals in Agriculture" In: Lepp NW, editor. Effect of heavy metal pollution on plants: Metals in the environment, Vol. II. London New Jersey: Applied Sci Publ, 84-159 